\title{
CARACTERIZAÇÃO DE PÓ DE BALÃO PARA APLICAÇÃO EM MASSA CERẨMICA PARA FABRICAÇÃO DE BLOCOS DE VEDAÇÃO*
}

\author{
César Augusto de Oliveira Gomesi ${ }^{1}$ \\ Rodolfo Augusto do Rosário Lira ${ }^{2}$ \\ Alisson Clay Rios da Silva ${ }^{3}$ \\ Sérgio Neves Monteiro ${ }^{4}$ \\ Verônica Scarpini Candido ${ }^{5}$
}

\section{Resumo}

Este estudo tem por objetivo caracterizar o pó de balão proveniente de uma siderúrgica do estado do Pará visando a sua incorporação em argilas para produção de blocos. O resíduo passou pela etapa de beneficiamento e, depois, foi realizada a difração de raios-X (DRX) e fluorescência de raios-X (FRX). Além disso, realizou-se também a análise morfológica por microscopia eletrônica de varredura (MEV). Os resultados mostraram que hematita, magnetita, goethita são as fases predominantes. A análise química por $\mathrm{FRX}$ mostrou que o resíduo apresenta baixos teores de sílica (SiO2) e alumina (Al2O3) associados a elevados teores de óxido de ferro III (Fe2O3). Dessa forma, a caracterização do pó de balão mostrou que esse resíduo apresenta-se como um potencial constituinte mássico cerâmico e que os elevados teores de óxido ferro podem contribuir para melhorar a cor dos produtos finais.

Palavras-chave: Blocos; Caracterização; Cerâmica Vermelha; Pó de Balão.

\section{CHARACTERIZATION OF "PÓ DE BALÃO” FOR APLICATION IN RED CERAMICS FOR THE PRODUCTION OF BRICKS}

\section{Abstract}

This study aims to characterize the "pó de balão from a steel mill in the state of Pará, aiming at its incorporation into clays for brick production. The residue passed through the processing step and X-ray diffraction (XRD) and X-ray fluorescence (XRD) were performed. In addition, morphological analysis was performed by scanning electron microscopy (SEM). The results showed that hematite, magnetite, goethite are the predominant phases. The chemical analysis by $\mathrm{FRX}$ showed that the residue presents low levels of silica (SiO2) and alumina (Al2O3) associated with high levels of iron oxide III (Fe2O3). Thus, the characterization of the pó de balão showed that this residue presents itself as a potential ceramic mass constituent and that the high levels of iron oxide can contribute to improve the color of the final products.

Keywords: Brick; Characterization; Pó de balão; Red Ceramics.

1 Graduando em Engenharia de Materiais, Faculdade de Engenharia de Materiais, Universidade Federal do Pará (UFPA), Ananindeua-PA, Brasil.

2 Graduando em Engenharia de Materiais, Faculdade de Engenharia de Materiais, Universidade Federal do Pará (UFPA), Ananindeua-PA, Brasil.

3 Químico industrial, Doutor em Ciência dos Materiais, Professor Adjunto I, Faculdade de Engenharia de Materiais, Universidade Federal do Pará (UFPA), Ananindeua-PA, Brasil.

4 Engenheiro de Materiais, PhD em Engenharia e Ciência dos Materiais, Professor, Programa de Pós-graduação em Engenharia de Materiais/Departamento de Engenharia mecânica e Materiais, Instituto Militar de Engenharia (IME), Rio de Janeiro, Rio de Janeiro, Brasil.

5 Bióloga, Doutora em Ciência dos Materiais, Professora Adjunta I, Faculdade de Engenharia de Materiais, Universidade Federal do Pará (UFPA), Ananindeua-PA, Brasil.. 


\section{INTRODUÇÃO}

As siderúrgicas são responsáveis por uma grande variedade de resíduos passíveis de reciclagem, que podem ter uma utilidade dentro do setor industrial, ou servirem como objetos de estudo para diversas aplicações. [1] Devido à crescente preocupação com as questões ambientais, várias indústrias passaram a investir em novas alternativas para solucionar os problemas decorrentes da sua geração de resíduos e disposição. [2]

Um desses resíduos é o pó de balão "carepa de laminação", que é basicamente um coproduto oriundo das operações de lingotamento e laminação do aço. $[3,4]$

O pó de balão consiste no material particulado fino carreado do alto-forno siderúrgico e que é retido em sistemas de limpeza de gases. O pó de balão é constituída por óxidos de ferro nas formas $\mathrm{FeO}, \mathrm{Fe} 2 \mathrm{O} 3$ e $\mathrm{Fe} 3 \mathrm{O} 4$, identificadas como wustita, hematita e magnetita, respectivamente. A disposição em pátios de resíduos deve ser realizada de acordo com os parâmetros das normas ambientais pertinentes ao setor. $[1,3,5]$

O resíduo da laminação já vem sendo estudado como material agregado em materiais cerâmicos, como em concreto de cimento Portland [6], em massas de cerâmica vermelha com variações na temperatura de sinterização ou com diferentes granulometrias [7].

A inserção do pó de balão em corpos de cerâmica vermelha requer uma análise de composição química e mineralógica para se obter formulações específicas, que colaborem na busca da melhoria nas propriedades dos materiais fabricados.[8] A caracterização físico-química das matérias-primas é fundamental para a obtenção de peças com propriedades finais desejadas, que juntamente ao conhecimento e controle de todas as etapas do processo industrial, podem eliminar ou reduzir os defeitos de fabricação, tais como: trincas, retração, compactação, fundência, absorção de água e resistência mecânica $[9,10]$.

O objetivo deste trabalho consiste em caracterizar o pó de balão proveniente da atividade siderúrgica do estado do Pará para sua utilização como constituinte mássico em argilas para produção de blocos de vedação.

\section{MATERIAIS E MÉTODOS}


O pó de balão foi obtido de uma siderúrgica localizada no estado do Pará e, após sua obtenção, o resíduo foi encaminhado à Usina de Materiais da Universidade Federal do Pará.

$\mathrm{O}$ pó de balão foi seco em estufa de modelo DIMATE, à temperatura de $110{ }^{\circ} \mathrm{C}$ durante $24 \mathrm{~h}$. Após essa etapa o material foi conduzido para o moinho de bolas de modelo Work Index série 005 , onde foi realizada a etapa de desagregação, por um período de 30 minutos.

Em seguida, o resíduo foi passado em peneira com abertura de 325 mesh e encaminhado para a análise mineralógica, química e morfológica. A difração de raios-X (DRX), foi realizada em amostras na forma de pó em difratômetro da Bruker, modelo D2Phaser, operando a $30 \mathrm{kV}$ e $10 \mathrm{~mA}$ e com um comprimento de onda $\lambda \mathrm{CuK} \alpha=1,5406 \AA$. As amostras foram examinadas em um intervalo de $2 \theta$ entre 0 e $60^{\circ}$, a uma taxa de varredura de $8 \% \min$.

A Fluorescência de raios-X (FRX) foi realizada utilizando o equipamento Axios Minerals da PANalytical e a análise morfológica das partículas foi feita utilizando um microscópio eletrônico de varredura de bancada Hitachi Analytical TableTop SEM TM3030.

A análise morfológica das partículas foi feita utilizando um microscópio eletrônico de varredura de bancada Hitachi Analytical TableTop SEM TM3030.

\section{RESULTADOS}

A tabela 1 apresenta o resultado da fluorescência de raios-x do pó de balão.

Tabela 1. Composição química do pó de balão

\begin{tabular}{ll}
\multicolumn{2}{c}{ Pó de balão } \\
\hline Componente & $\begin{array}{l}\% \text { em } \\
\text { peso }\end{array}$ \\
\hline $\mathrm{SiO} 2$ & 3,56 \\
$\mathrm{Al} 2 \mathrm{O} 3$ & 1,85 \\
$\mathrm{Fe} 2 \mathrm{O} 3$ & 37,2 \\
$\mathrm{TiO} 2$ & 0,18 \\
$\mathrm{MnO}$ & 0,41 \\
$\mathrm{MgO}$ & 0,39 \\
$\mathrm{CaO}$ & 6,90 \\
$\mathrm{~K} 2 \mathrm{O}$ & 0,42 \\
$\mathrm{SO} 3$ & 0,60 \\
$\mathrm{ZnO}$ & 0,18 \\
$\mathrm{Cl}$ & 0,22 \\
$\mathrm{PF}$ & 48,01 \\
\hline
\end{tabular}

Nota-se que o pó de balão apresenta elevados teores de óxido de ferro. Esse resultado pode contribuir para conferir à cerâmica queimada a coloração avermelhada. As argilas encontradas no estado do Pará, geralmente, possuem baixos teores de óxidos de ferro o que confere as peças finais uma cor mais clara. 
Dessa forma, a incorporação do pó pode induzir uma melhoria na cor do produto final.

A análise por difração de raios-x (DRX) da lama de alto forno está apresentada na figura 1.

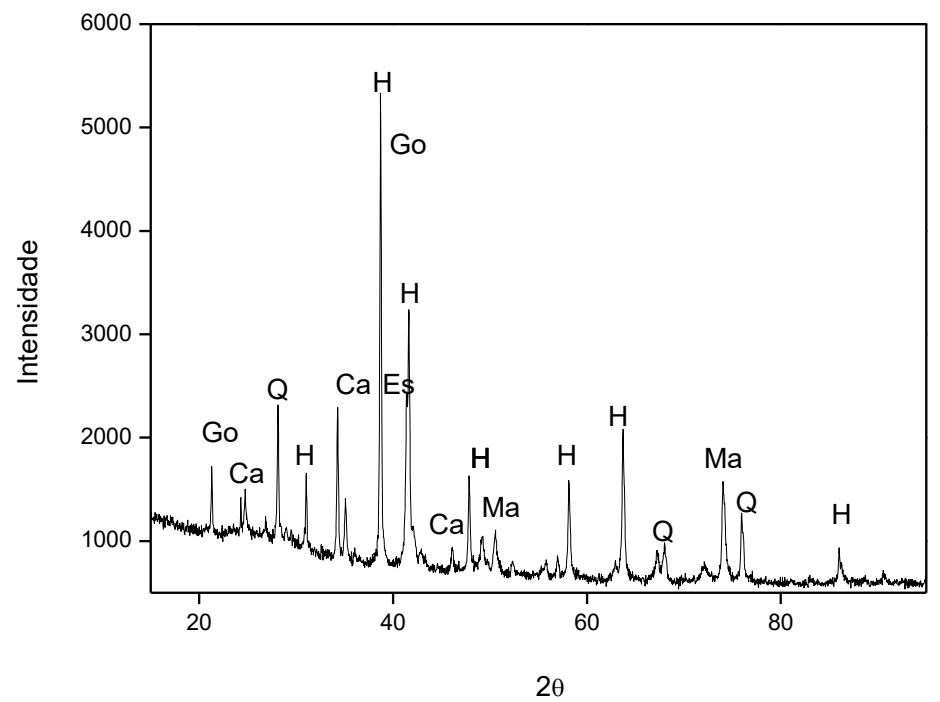

Figura 1. Difratograma de raios-x do pó de balão. Ca: calcita, Es: espinélios, Go: goetita, H: hematita M: magnetita, Q: quartzo.

A análise por difratometria de raios-x revelou a presença de fases como a hematita, e magnetita que estão associadas a compostos de ferro. Além dessas fases associadas a óxidos ferro, fases como calcita e quartzo também foram observadas.

Devido à composição química complexa, vale ressaltar que podem existir outras fases cristalinas minoritárias. Outro aspecto importante que vale a pena citar é a presença de finos de coque nesse tipo de resíduo que não puderam ser identificados devido ao seu caráter amorfo.

Ao correlacionar a fluorescência de raios- $x$ com a difração de raios-x pode-se afirmar que a elevada perda ao fogo observada pode estar relacionada à descarbonetação da calcita além da desidroxilação e/ou desidratação da goetita.

A micrografia obtida por MEV do pó de balão está apresentada na figura 2.

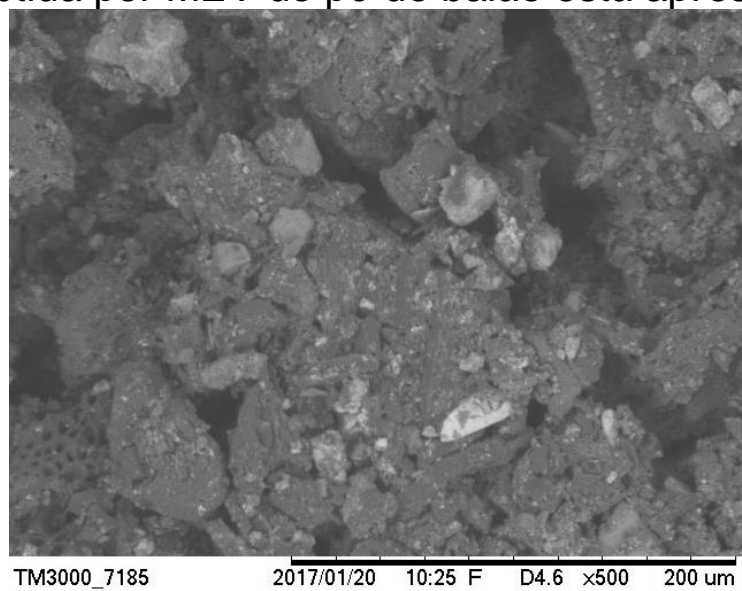

Figura 2. Micrografia obtida por MEV do pó de balão com aumento de 500x. 
Nota-se que o pó de balão é composto por partículas mais claras que podem estar associadas ao quartzo e partículas de coloração mais escuras que podem estar associadas ao ferro. Observa-se também que as partículas não apresentam um padrão morfológico sendo possível observar partículas com diferentes formatos.

Dessa forma, a caracterização do pó de balão revelou que esse resíduo pode ser um material que pode contribuir para intensificar a cor das cerâmicas queimadas e, pode contribuir para melhorar o desempenho tecnológico das peças.

\section{CONCLUSÃO}

A caracterização do pó de balão revelou que o resíduo é rico em óxidos de ferro. As fases cristalinas presentes são hematita associada ao óxido de ferro III, a magnetita e goetita, todas essas associadas ao ferro, calcita associada ao óxido de cálcio e quartzo relacionado à Sílica. A análise por MEV mostrou a presença de partículas que podem estar associadas ao quartzo e aos óxidos de ferro. Assim, pode-se inferir que o pó de balão pode ser um potencial resíduo utilizado na composição mássica das argilas podendo contribuir para alcançar valores de resistência mecânica e absorção de água exigidos por norma.

\section{REFERÊNCIAS}

1 JG Meller, ABC Arnt, MR Rocha. Desempenho de massa cerâmica vermelha com adição de carepa/resíduo de laminação em diferentes temperaturas de queima. $21^{\circ}$ CBECIMAT - Congresso Brasileiro de Engenharia e Ciência dos Materiais. Cuiabá, MT, 2014.

2 CMF Vieira, SN Monteiro. Incorporation of solid wastes in red ceramics - an updated review. Revista Matéria. 2009; 14(3): 881 - 905.

3 ASS Neves. Caracterização física e química da carepa de laminação para estudo em sinterização. 56 Congresso Brasileiro de Química _CBQ, Belém-PA, 2016.

4 FA Cunha, G Araújo Filho, A Martins Júnior, OC̄B Gomes, OS Assis. Aspectos técnicos da utilização da carepa gerada em processos siderúrgicos e tratada por desagregação ultra-sônica. Tecnologia em Metalurgia e Materiais. 2006; 3(2):1-5.

5 ABC Arnt. Influência da temperatura de sinterização em cerâmica vermelha com adição de carepa/resíduo de laminação. 19 Congresso Brasileiro de Engenharia e Ciência dos Materiais - CBECIMAT, Campos do Jordão - SP, 2010.

6 FM Pereira, JCK Verney, DM Lenz. Avaliação do emprego da carepa de aço como agregado miúdo em concreto. Revista Esc. Minas. 2011; 64(4): 463-469.

7 ABC Arnt, MR Rocha, JG Meller. Influência na aplicação de diferentes granulometrias de carepa (resíduo) de laminação em massa cerâmica vermelha. 56ํㅡㄹ Congresso Brasileiro de Cerâmica - CBC, Curitiba - PR, 2012.

8 JN Galdino. Influência do teor e granulometria da calcita e da temperatura de sinterização no desenvolvimento de massas cerâmicas para revestimento poroso (BIII). Tese (Doutorado) - Programa de Pós-graduação em Engenharia Química. Universidade Federal do Rio Grande do Norte. Natal - RN, 2010.

9 PS Santos. Ciência e Tecnologia das Argilas. $2^{\underline{a}}$ edição revisada e ampliada. São Paulo: Edgard Blücher Ltda. 1989.

10 MRC Oliveira, J Martins. Caracterização e classificação do resíduo sólido "pó do balão", gerado na indústria siderúrgica não integrada a carvão vegetal:- estudo de um caso na região de Sete Lagoas/MG. Química Nova. 2003; 26(1): 5-9. 